\title{
Percentage* of Adults Aged $\geq 20$ Years Consuming Breakfast on a Given Day, by Sex and Age — United States, 2015-2018
}

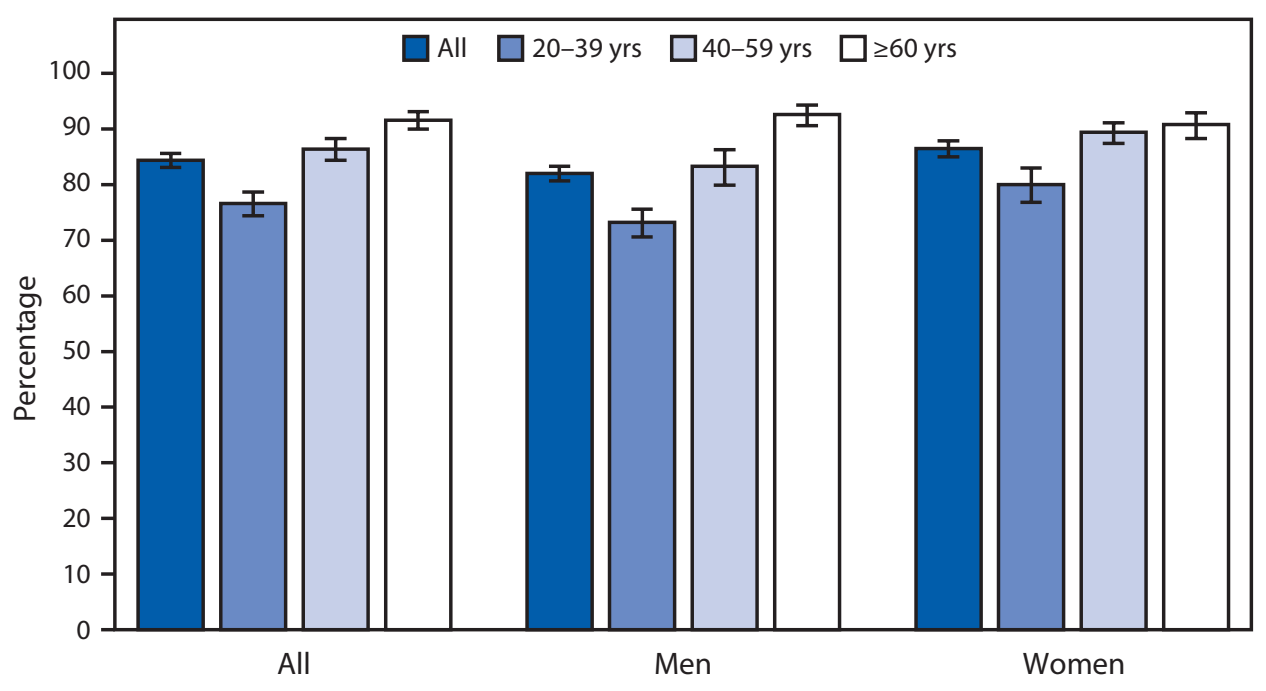

* Percentages are based on reporting breakfast as the eating occasion for a food or beverage during the in-person 24-hour dietary recall; 95\% confidence intervals are indicated with error bars.

During $2015-2018,84.4 \%$ of adults aged $\geq 20$ years consumed breakfast on a given day, with the percentage increasing with age, from $76.6 \%$ among adults aged $20-39$ years, to $86.4 \%$ among adults aged $40-59$ years, and $91.6 \%$ among those aged $\geq 60$ years. A higher percentage of women consumed breakfast compared with men among all adults $\geq 20$ years ( $86.5 \%$ versus $82.0 \%$ ), those aged $20-39$ years ( $80.0 \%$ versus $73.2 \%$ ), and those aged $40-59$ years (89.4\% versus $83.3 \%$ ). No significant differences were observed by sex for adults aged $\geq 60$ years ( $90.8 \%$ women and $92.6 \%$ men).

Source:Terry, AL, Wambogo E. National Health and Nutrition Examination Survey, Dietary Data, 2015-2018; https://www.cdc.gov/nchs/nhanes/ index.htm.

Reported by: Ana Terry, MS, auc5@cdc.gov, 301-458-4227; Edwina Wambogo, PhD. 